\title{
Screening for distress, the 6th vital sign: common problems in cancer outpatients over one year in usual care: associations with marital status, sex, and age
}

Janine Giese-Davis ${ }^{1,2,5^{*}}$, Amy Waller ${ }^{1,2}$, Linda E Carlson ${ }^{1,2}$, Shannon Groff', Lihong Zhong ${ }^{1,2}$, Eric Neri ${ }^{3}$, Sacha M Bachor ${ }^{1}$, Jassandre Adamyk-Simpson ${ }^{1}$, Kate MS Rancourt ${ }^{4}$, Bernie Dunlop ${ }^{1}$ and Barry D Bultz ${ }^{1,2}$

\begin{abstract}
Background: Very few studies examine the longitudinal prevalence of problems and the awareness or use of clinical programs by patients who report these problems. Of the studies that examine age, gender and marital status as predictors of a range of patient outcomes, none examines the interactions between these demographic variables. This study examined the typical trajectory of common practical and psychosocial problems endorsed over 12 months in a usual-care sample of cancer outpatients. Specifically, we examined whether marital status, sex, age, and their interactions predicted these trajectories. We did not actively triage or refer patients in this study in order to examine the natural course of problem reports.

Methods: Patients completed baseline screening ( $N=1196$ of 1707 approached) and the sample included more men $(N=696)$ than women $(N=498)$, average age 61.1 years. The most common diagnoses were gastrointestinal (27.1\%), prostate (19.2\%), skin (11.1\%) and gynecological (9.2\%). Among other measures, patients completed a Common Problem Checklist and Psychosocial Resources Use questions at baseline, 3, 6, and 12 months using paper and pencil surveys.

Results: Results indicated that patients reported psychosocial problems more often than practical and both decreased significantly over time. Younger single patients reported more practical problems than those in committed relationships. Younger patients and women of all ages reported more psychosocial problems. Among a number of interesting interactions, for practical problems, single older patients improved more; whereas among married people, younger patients improved more. For psychosocial problems we found that older female patients improved more than younger females, but among males, it was younger patients who improved more. Young single men and women reported the most past-and future-use of services.

Conclusions: Younger women are particularly vulnerable to experiencing practical and psychosocial problems when diagnosed with cancer, but being married protects these younger women. Marriage appeared to buffer reports of both practical and psychosocial problems, and led to less awareness and use of services. Unexpectedly, young men reported the highest use of psychosocial services. This study informs clinical program development with information on these risk groups.
\end{abstract}

Keywords: Marital status, Age, Sex, Cancer, Oncology, Screening for distress, Common problems

\footnotetext{
* Correspondence: jgieseda@ucalgary.ca

'Department of Psychosocial Resources, Tom Baker Cancer Centre, Calgary,

Canada

${ }^{2}$ Department of Oncology, University of Calgary, Calgary, California

Full list of author information is available at the end of the article
} 


\section{Background}

The National Comprehensive Cancer Network (NCCN) defines distress as an unpleasant psychological, social, and/or spiritual experience that interferes with effective coping [1]. Despite prevalence rates that can range from $35-60 \%$ in the cancer population [2-5], distress often goes unrecognized [6-10] and can have negative implications for patients including reduced health-related quality of life [11], greater long-term distress [12], poor satisfaction with medical care [13], and possibly reduced survival $[14,15]$. Common psychosocial, practical and physical problems may amplify feelings of distress, and their assessment offers clinicians opportunities to refer patients specifically to professionals who can address these patient problems. In this paper, we examine predictors of these common problems in order to facilitate strategic targets for offering psychosocial service.

Patients most frequently report physical, emotional and informational problems [11,16-18]; and these problems consistently predict clinical distress [3,11,17-19]. Some, but not all [18] researchers find that practical problems may also predict distress $[3,11,19]$. Other distressing problems may include social [20], financial [11,16,21], cognitive [3], sexual [22,23] and family related problems $[3,11,16,24]$, and problems relating to the quality of cancer care received including care coordination [25] and relationships with health professionals $[16,24,25]$.

Given the high prevalence of distress and common problems that may be present in the cancer population and the detrimental impact both can have on wellbeing, analyzing common problems and identifying characteristics of people who are more likely to report particular problems could facilitate planning for targeted clinical services [26]. Unmarried, younger and female patients report greater practical problems in mixed [21,24,27,28], as well as diagnostically homogenous populations [23,29,30]. Marriage also appears to buffer the number of problems patients report [27,31-34]. These associations include problems with finances $[21,24,27,28]$, insurance [21,27,31], drug coverage [35] and employment issues [27,30,31]; as well as transportation [33], help around the home $[27,33]$ and childcare [24]. Others report no differences in problems according to demographic characteristics [36].

Women report greater psychological, patient care and support [24,26,37], and sexuality problems [37]. Younger people report more psychological [24,27,31,37], patient care and support [38], information [24,27,31,37], social $[21,27,31]$, physical and treatment-specific [21,31], sexual $[23,30,37,38]$ and spiritual problems $[24,27,31,37]$. The association between marital status and psychosocial problems is less consistent; perhaps due to differing study settings and populations [16,29,39-41]. Variations in the measures used to assess problems, the population assessed, and the timing of assessments may contribute to these conflicting results [42].

Very few studies examine the longitudinal prevalence of problems and the awareness or use of clinical programs by patients who report these problems [26,38]. Of the studies that examine age, gender and marital status as predictors of a range of patient outcomes, none examines the interactions between these demographic variables. For example, do younger women experience psychological problems in the same way as older women and do these associations change over time? By examining how these demographic variables interact with each other, we may be better equipped to identify subgroups of people that may be more at risk for specific problems and facilitate the early identification and management of these issues before they become too overwhelming. As part of a comprehensive Screening for Distress the 6th Vital Sign in Cancer Care Program [43] adopted by a number of provinces across Canada, this study examined a naturalistic course of usual care without triage to document clinical outcomes and gaps in service. We have previously published usual-care baseline and longitudinal trajectories of distress, anxiety and depression, pain and fatigue [44], and this analysis not only adds to the literature, but also facilitates clinicians' ability to directly modify the services they offer.

Because few studies examine common problems over time and their associations with distress, we first check these associations. We then test our primary hypotheses specifically examining associations between age, gender, and marital status as they interact and predict psychosocial and practical problems. Lastly, we examine secondary hypotheses relating to past, present, and future resource use.

\section{Check of associations between problems and distress}

We examined whether practical and psychosocial problems correlated significantly with distress at baseline and over 12 months.

\section{Primary hypotheses}

1. Being married, partnered, or in a committed relationship will buffer (or lower) reports of practical and psychosocial problems, both at baseline and over time.

2. Younger single, divorced, widowed, or separated women will represent a risk group for greater need in both practical and psychosocial problems.

\section{Secondary hypotheses}

3. Due to these lower needs/problems, being married will lead to less awareness of and past, current, or 
anticipated use of psychosocial services. Due to these higher needs/problems younger or single women will report greater awareness, past, current, and anticipated use of services.

\section{Method \\ Participants}

Research assistants (RAs) approached ambulatory oncology patients (over 18) attending the Tom Baker Cancer Centre (TBCC) Outpatient Clinics who were new to $\mathrm{TBCC}$, to that particular clinic, or to the scheduled oncologist, to participate in this study approved by the Conjoint Health Research Ethics Board of the University of Calgary. Research assistants excluded patients who did not read or speak English and did not have an interpreter with them, or patients deemed too ill (e.g., arrived in a stretcher). In total, 1196 (70\%) patients signed informed consent and participated (511 of 1707 eligible were missed, excused, or refused to participate: Figure 1). A more detailed description of the study trial methodology has previously been reported $[44,45]$.

\section{Measures}

Demographics and cancer history: We assessed age, sex, marital status, living arrangements (alone or with others), education, ethnic/cultural background, income, source of income, first language, type of cancer and type of treatment, and the Alberta Cancer Registry provided

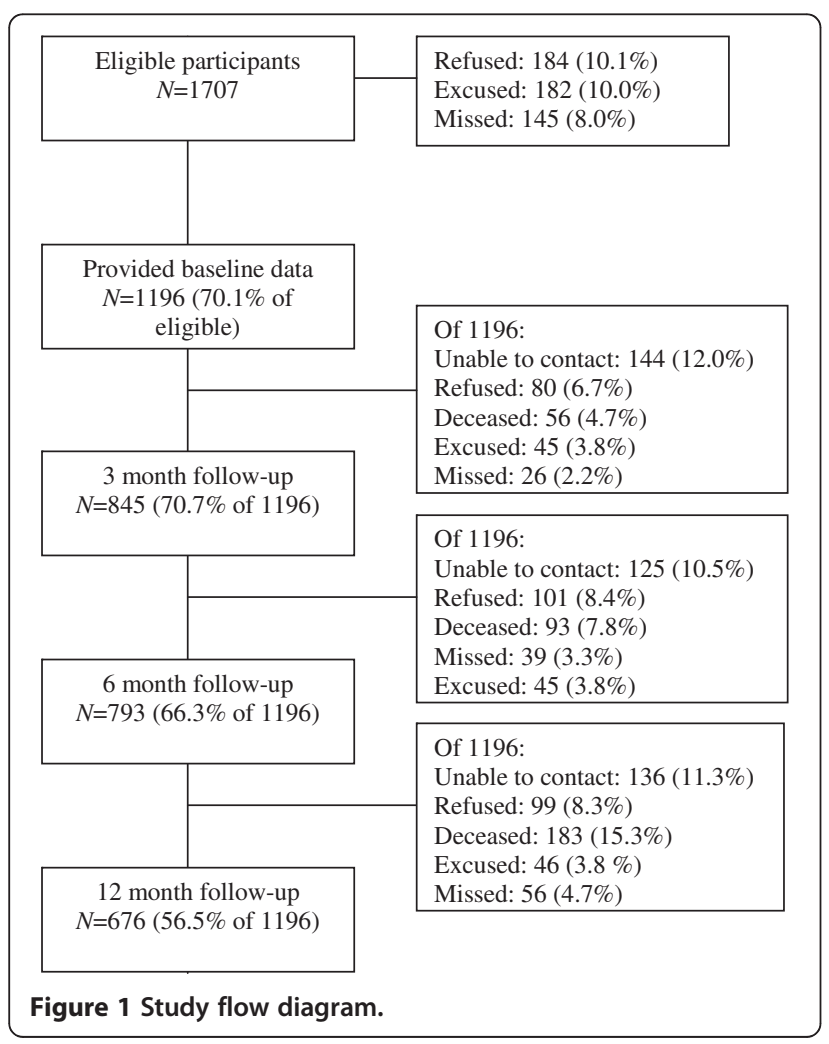

information on whether patients had primary or metastatic diagnoses.

The Modified Problem Checklist (PCL). Adapted to the Canadian setting from the original list published by the $\mathrm{NCCN}$, this list contains the 7 most common practical problems in our settings (accommodation, transportation, parking, drug coverage, work/school, income/finances, and groceries); and 13 psychosocial problems (burden to others, worry about family/friends, talking with family, talking with medical team, family conflict, changes in appearance; alcohol/drugs, smoking, coping, sexuality, spirituality, treatment decisions and sleep). Participants indicate the presence or absence of each problem in the preceding week [46].

Awareness and Use of Psychosocial Resources. Four questions assessed patients' awareness and use of Psychosocial Resources: whether the patient is aware that a Psychosocial Department exists, whether the patient has used, or is currently using those services, and if the patient intends to use those services in the future.

Distress Thermometer (DT): Patients rated their average distress in the last week on a scale ranging from 0 "not at all" to 10 "extreme distress" [46]. The Distress Thermometer has been validated against the HADS, BSI, CES-D and clinical diagnosis in patients with mixed diagnoses and stages of disease [47]. A review of diagnostic validity studies reported a pooled sensitivity of $77.1 \%$ and specificity of $66.1 \%$ [48].

The psychological screen for cancer (PSSCAN Part C) [49,50]: Patients rated their anxiety and depression using 10 items rated on a 5 point Likert scale, ranging from "not at all" to "very much so". [49,50]. Cronbach alphas ranged from .79 to .89 and test-retest stabilities ranged from .49 to $.87[49,50]$.

\section{Procedure}

RAs assessed daily TBCC clinic lists and identified eligible patients. Once the patient checked in, they approached the patient to explain the study. If the patient consented to participate, the RA asked them to complete the questionnaires while at the clinic. Once completed, patients deposited the questionnaires into a designated box. If patients chose not to participate, they checked off their reason for not doing so (or the RA asked them and did this) and submitted the uncompleted questionnaires.

RAs contacted patients 3, 6, and 12-months later via e-mail or telephone. If the patient provided an e-mail address during their initial assessment, RAs sent them an automated email inviting them to complete the follow-up on-line. If they did not respond one week after the reminder, RAs added their name to the automatically generated phone list and contacted them by telephone. RAs made 3 calls at different times of the 
day, at least one of which was in the evening/weekend, before marking patients as "unable to contact".

\section{Data analysis}

First we examined the prevalence of common practical and psychosocial problems through baseline descriptive statistics. In order to examine baseline and over-time totals, we summed practical and psychosocial problems separately. We Winsorized these measures to adjust for a skewed distribution so that all summed total scores above 5 were set to equal 5 and examined baseline averages for each summary category.

\section{Check of whether common problems correlate with distress} We examined the association between Practical and Psychosocial problems and patient reported distress, anxiety and depression at baseline using Spearman correlations. We then calculated a slope of outcome on time (measured in months) using standard linear regression [51] for each participant who provided data at baseline and at least one follow-up. We examined the association between Practical and Psychosocial problem slopes and each of the distress, anxiety and depression slopes using Spearman correlations (as effect-size estimates).

\section{Primary analyses}

We investigated associations between marital status, sex, and age and practical and psychosocial problems at baseline and over time using two Hierarchical Linear Model (HLM) equations with random-effect co-variance structures, one with practical problems as the dependent measure and one with psychosocial problems (Proc Mixed SAS). Independent variables included Time, Age (as a continuous variable), Sex, Marital Status (married/partnered vs. not married), and all interactions centered [52]. We report results for associations at baseline, and for interactions with time which represent change over time in dependent variables.

In secondary analyses, we examined whether Age, Sex, and Marital Status predicted Awareness, Past, Current, and Future Use of Psychosocial Resources. We conducted four logistic regressions with binary dependent variables representing the four Awareness and Use Categories. The independent variables were marital status, sex, age, and all the interactions, all centered [52].

Lastly, we examined whether stage of disease (primary vs. metastatic) and type of treatment (surgery, chemotherapy, radiation, hormone therapy) could explain our results. In order for our results to be proxies for these underlying prognostic variables, we would have to find significant correlations between the prognostic variables and both hypothesized independent (IVs) and dependent (DVs) variables. We tested these associations using Spearman Correlations. Any prognostic variable significantly correlated with both IVs and DVs would then be included in adjusted HLM and logistic regression models.

HLM models were analysed using SAS Version 9.2 (SAS Institute Inc., NC, USA, 2007). All remaining data were analysed using Statistical Package for the Social Sciences (SPSS) Version 19.

\section{Results}

\section{Demographics and medical information}

Of the 1707 patients we approached to participate during the recruitment period, 1196 (71\%) provided baseline data (see Figure 1- recruitment diagram). The average age of the sample was $61.1(S D=14.5)$ years, $58 \%$ were male and $74 \%$ were married, common-law, or in a committed relationship (Table 1). The largest tumor groups were gastrointestinal (27.1\%), prostate, (19.2\%), and skin (11.1\%). The majority of patients had primary $(69 \%)$ rather than metastatic (13\%) diagnoses.

\section{Prevalence of common problems}

Figure $2 \mathrm{a}$ and $2 \mathrm{~b}$ present the percentage of patients at each time point endorsing each of the problems on the CPC. Patients endorsed psychosocial problems at greater percentages $(M=16.9 \%$ for psychosocial; $M=13.4 \%$ for practical at baseline) and higher levels $(M=2.20, S D=2.08)$ than practical $(M=0.94, S D=1.37)$ problems. The top 4 highest percentages of endorsement were for psychosocial problems (Worry about friends/family $(M=42.0 \%)$, Sleep $(M=33.8 \%)$, Being a burden to others $(M=29.0 \%)$ and Coping $(M=21.4 \%))$. The fifth highest was Finances $(M=19.4 \%)$, which were the most commonly endorsed of practical problems, and remained high over time (Figure 2a). Endorsement of Worry about friends/family and Sleep also remained high over time (Figure $2 \mathrm{~b}$ ).

\section{Check of whether common problems correlate with distress}

The number of practical problems reported at baseline was positively correlated with baseline distress, anxiety, and depression scores. The relationship between the number of psychosocial problems and distress, anxiety, and depression was stronger (Table 2).

Practical problems declined and correlated at a low level with distress, and anxiety over time, but the relationship with depression was very small (Table 2). Psychosocial problems slopes significantly correlated with distress, anxiety, and depression slopes with all outcomes declining over time (Table 2).

\section{Primary analyses}

\section{Baseline practical and psychosocial problems}

In the HLM analysis, we found a significant 2-way interaction (Age x Marital Status) for practical problems (Table 3). Overall, younger patients reported more practical problems than older patients at baseline; within each 
Table 1 Participant demographic, medical, and study variables for participants in usual care study at baseline Demographic, medical, and study variables Baseline $(n=1196)$ $N$ or Mean $\%$ or $S D$

Mean number problems

\begin{tabular}{lll}
\hline Practical & 0.94 & 1.37 \\
\hline Psychosocial & 1.96 & 1.91 \\
\hline Mean slope of change in problems & & \\
\hline Practical & -0.05 & 0.18 \\
\hline Psychosocial & -0.03 & 0.25 \\
\hline
\end{tabular}

Psychosocial Resources (\% endorsed)

\begin{tabular}{lcc}
\hline Awareness & 595 & 50.8 \\
\hline Past use & 87 & 7.4 \\
\hline Current use & 14 & 1.2 \\
\hline Future use & 94 & 8.0 \\
\hline Age (years) & 61.10 & 14.51 \\
\hline Gender & & \\
\hline Male & 698 & 58.3 \\
\hline Female & 498 & 41.7
\end{tabular}

Marital status

\begin{tabular}{lcc}
\hline Single & 94 & 7.9 \\
\hline Married & 779 & 65.1 \\
\hline Separated & 32 & 2.7 \\
\hline Divorced & 78 & 6.5 \\
\hline Widow/er & 102 & 8.5 \\
\hline Common Law & 66 & 5.5 \\
\hline Committed & 22 & 1.8 \\
\hline Missing & 23 & 1.9 \\
\hline Living arrangements & & \\
\hline Not Alone & 969 & 84.1 \\
\hline Alone & 183 & 15.9 \\
\hline Education & &
\end{tabular}

\section{Education}

\begin{tabular}{lcc}
\hline Elementary School (1-6) & 30 & 2.5 \\
\hline Middle School (7-9) & 106 & 8.9 \\
\hline High School (10-12) & 401 & 33.5 \\
\hline Community College & 235 & 19.6 \\
\hline Some University & 115 & 9.6 \\
\hline Completed University & 167 & 14.0 \\
\hline Postgraduate & 112 & 9.4 \\
\hline $\begin{array}{l}\text { Missing } \\
\text { Ethnicity }\end{array}$ & 30 & 2.5 \\
\hline $\begin{array}{l}\text { English as first language and visible } \\
\text { majority }\end{array}$ & 992 & 82.9 \\
$\begin{array}{l}\text { English as first language and visible } \\
\text { minority }\end{array}$ & 46 & 3.8 \\
\hline $\begin{array}{l}\text { English not first language and visible } \\
\text { majority }\end{array}$ & 75 & 6.3 \\
\hline $\begin{array}{l}\text { English not first language and visible } \\
\text { minority }\end{array}$ & 55 & 4.6 \\
\hline \begin{tabular}{l} 
Missing \\
\hline
\end{tabular} & 28 & 2.3 \\
\hline
\end{tabular}

Table 1 Participant demographic, medical, and study variables for participants in usual care study at baseline (Continued)

\section{Family income}

\begin{tabular}{lcc}
\hline Less than $\$ 30,000$ & 215 & 18.0 \\
\hline Between $\$ 30,001$ and $\$ 49,999$ & 270 & 22.6 \\
\hline Between $\$ 50,000$ and $\$ 79,999$ & 173 & 14.5 \\
\hline Between $\$ 80,000$ and $\$ 99,999$ & 117 & 9.8 \\
\hline more than $\$ 100,000$ & 180 & 15.1 \\
\hline Prefer not to say & 195 & 16.3 \\
\hline Missing & 46 & 3.8 \\
\hline Source income & & \\
\hline Pension/Retirement (CPP) & 446 & 37.3 \\
\hline Employment & 443 & 37.0 \\
\hline Family members (spouse/parent) & 123 & 10.3 \\
\hline Social assistance & 54 & 4.5 \\
\hline Prefer not to say & 55 & 4.6 \\
\hline Other & 38 & 3.2 \\
\hline Missing & 37 & 3.1 \\
\hline Dis & &
\end{tabular}

\section{Diagnosis}

\begin{tabular}{lcc}
\hline Gastrointestinal & 329 & 27.5 \\
\hline Prostate & 230 & 19.2 \\
\hline Skin (melanoma) & 133 & 11.1 \\
\hline Gynecological & 110 & 9.2 \\
\hline Head and neck & 75 & 6.3 \\
\hline Breast & 69 & 5.8 \\
\hline Lymphoma & 49 & 4.1 \\
\hline Leukemia & 39 & 3.3 \\
\hline Testicular & 33 & 2.8 \\
\hline Lung & 31 & 2.6 \\
\hline Thyroid & 25 & 2.1 \\
\hline Brain & 25 & 2.1 \\
\hline Other & 48 & 4.0
\end{tabular}

\section{Stage of disease}

\begin{tabular}{lcc}
\hline Primary & 824 & 68.9 \\
\hline Metastatic & 153 & 12.8 \\
\hline Missing/Not Staged & 219 & 18.3 \\
\hline
\end{tabular}

\section{Receipt of treatment prior to baseline}

\begin{tabular}{lcc}
\hline Surgery & 275 & 23.0 \\
\hline Chemotherapy & 100 & 8.4 \\
\hline Radiation therapy & 32 & 2.7 \\
\hline Transplant & 1 & 0.1 \\
\hline Hormone therapy & 50 & 4.2 \\
\hline
\end{tabular}

age group, single patients reported more practical problems than married patients (Figure 3). We found no significant interaction in the HLM analysis of psychosocial problems at baseline. Main effects were that age and sex predicted psychosocial problems (Table 4); younger 

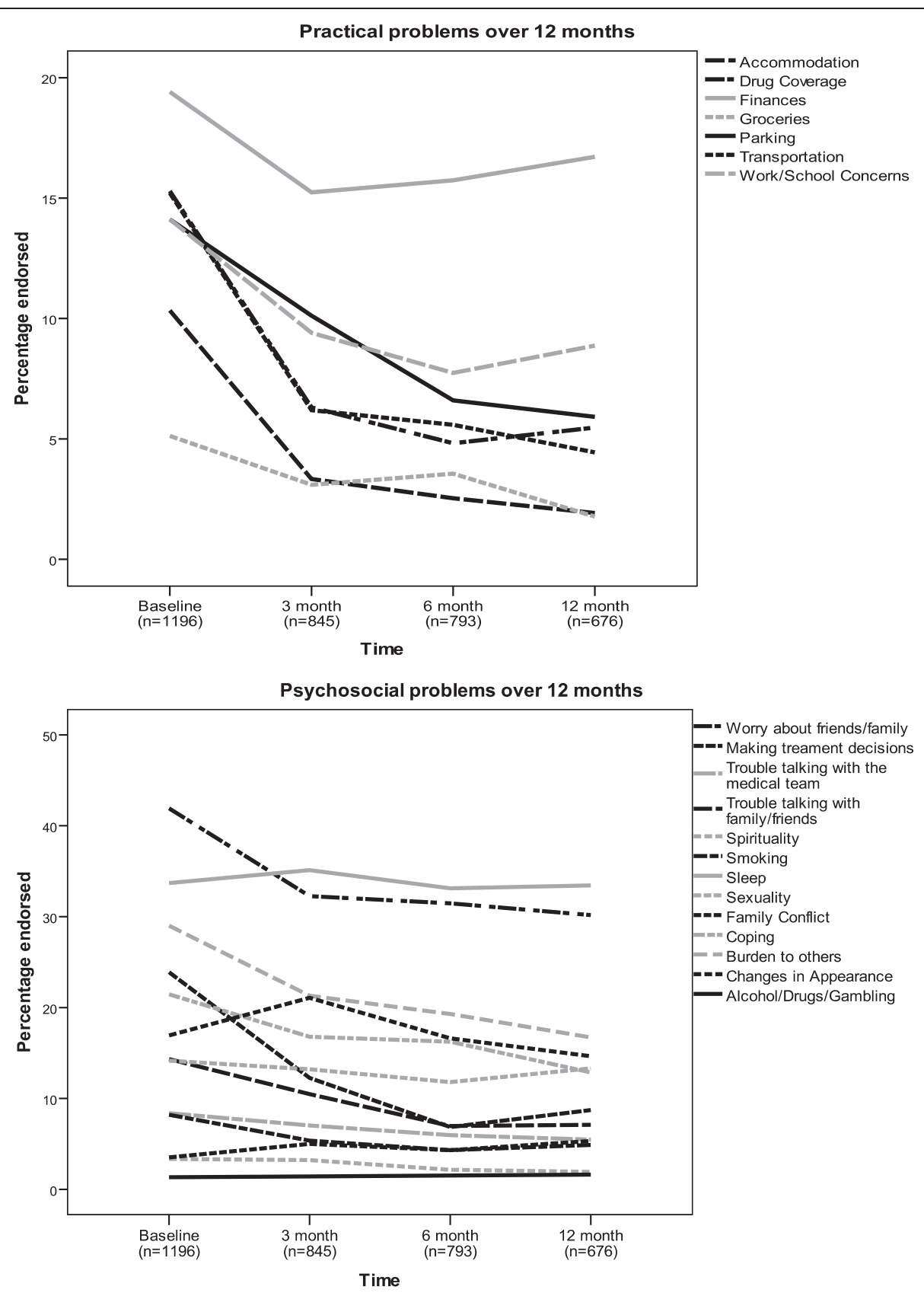

Figure 2 a and b: Percentage of patients endorsing Canadian problem Checklist items at each time point.

patients and females reported more psychosocial problems than males (Figure 4).

\section{Change over 12 months in practical and psychosocial problems}

In HLM analyses (Table 3), a main effect of time indicated that practical problems decreased significantly during the 12 months of the study. A significant 3-way interaction (Age x Marital Status x Time) indicated that for singles, older patients improved more than younger patients over time; whereas for married people, younger patients improved more over time). Younger, single patients were the most elevated at baseline and remained so at 12 months (Figure 3).

In HLM analyses (Table 4), a main effect of time indicated that psychosocial problems decreased significantly during the 12 months of the study. A significant 3-way interaction (Age $x$ Sex $x$ Time) for psychosocial problems indicated that among females, older patients improved more over time in psychosocial problems; among males, younger patients improved more over time (Figure 4). Younger females were the most elevated at baseline and 
Table 2 Correlations between total number of practical and psychosocial problems and distress thermometer (DT) scores at baseline and over time

\begin{tabular}{llll}
\hline & Mean (SD) & Correlation with practical problems & Correlation with psychosocial problems \\
\hline Baseline scores & & & - \\
\hline Total Practical problems & $0.94(1.37)$ & - & - \\
\hline Total Psychosocial problems & $2.20(2.08)$ & $.386^{* *}$ & $.526^{* *}$ \\
\hline Distress Thermometer (DT) & $3.89(2.89)$ & $.278^{* *}$ & $.444^{* *}$ \\
\hline Depression (PSSCAN) & $6.46(3.07)$ & $.225^{* *}$ & $.508^{* *}$ \\
\hline Anxiety (PSSCAN) & $8.72(4.09)$ & $.270^{* *}$ & - \\
\hline Over 12 months (slope) & & & - \\
\hline Total Practical problems & $-.05(0.29)$ & - & $.266^{* *}$ \\
\hline Total Psychosocial problems & $-.05(0.18)$ & $.114^{* *}$ & $.356^{* *}$ \\
\hline Distress Thermometer (DT) & $-.11(0.47)$ & $.098^{* *}$ & $.221^{* *}$ \\
\hline Depression (PSSCAN) & $-.05(0.34)$ & $.124^{* *}$ & $.324^{* *}$
\end{tabular}

${ }^{*} p<0.05 ;{ }^{* *} p<0.001$

remained the most elevated at 12 months. Main effects were that married patients declined more than single patients (Table 4).

\section{Secondary analysis}

Awareness, past, current, and future use of

psychosocial resources

Awareness of Psychosocial Resources available through

Cancer Care at baseline was significantly related to sex;

Table 3 Results from hierarchical linear model analysis of the impact of age, sex, and marital status on report of practical problems at baseline and over 12 months $(\mathrm{N}=1196)$

\begin{tabular}{|c|c|c|c|c|}
\hline & \multicolumn{3}{|c|}{ HLM on practical problems } & \multirow[t]{2}{*}{$E S$} \\
\hline & Estimate & T-value & $P$ & \\
\hline \multicolumn{5}{|l|}{ Baseline } \\
\hline Age & -0.018 & -8.08 & $<.0001$ & -0.02 \\
\hline Sex & -0.044 & -0.60 & 0.55 & -0.04 \\
\hline Marital Status & -0.299 & -4.12 & $<.0001$ & -0.26 \\
\hline Age $\times$ Sex & -0.004 & -0.92 & 0.36 & -0.004 \\
\hline Age x Marital Status & -0.009 & -2.05 & 0.04 & -0.01 \\
\hline Sex $\times$ Marital Status & -0.248 & -1.71 & 0.09 & -0.22 \\
\hline Age $\times$ Sex $\times$ Marital Status & 0.017 & 1.88 & 0.06 & 0.02 \\
\hline \multicolumn{5}{|l|}{ Over 12 Months } \\
\hline Time & -0.04 & -9.46 & $<.0001$ & -0.04 \\
\hline Age $\times$ Time & 0.0005 & 1.70 & 0.09 & 0.0004 \\
\hline Sex $x$ Time & 0.0006 & 0.07 & 0.95 & 0.0005 \\
\hline Marital Status x Time & 0.009 & 1.08 & 0.28 & 0.008 \\
\hline Age $\times$ Sex $\times$ Time & 0.0001 & 0.25 & 0.80 & 0.0001 \\
\hline Age $\times$ Marital Status $\times$ Time & 0.001 & 2.02 & 0.04 & 0.001 \\
\hline Sex $\times$ Marital Status $\times$ Time & 0.021 & 1.26 & 0.21 & 0.02 \\
\hline $\begin{array}{l}\text { Age } \times \text { Sex } \times \text { Marital } \\
\text { Status } \times \text { Time }\end{array}$ & -0.0006 & -0.56 & 0.58 & -0.001 \\
\hline
\end{tabular}

more females $(53.1 \%)$ than males $(49.1 \%)$ reported awareness $(O R=1.328, S E=0141,95 \%$ CI $(1.008,1.750)$, $p=.043)$. Current use of Psychosocial Resources available through Cancer Care was not significantly related to Age, Sex, and Marital Status (though a trend for marital status for current use would suggest that fewer married/ partnered men and women were using Psychosocial Resources $(O R=0.32, S E=0.603,95 \%$ CI $(0.099,1.050)$, $p=.06)$.

More single (11\%) than married people $(6.2 \%)$ reported past use of Psychosocial Resources $(O R=0.532, S E=0.254$, 95\% CI $(0.323,0.876), p=.013)$. The three-way Age $x$ Sex $\mathrm{x}$ Marital Status interaction suggests that more young single men $(18.8 \%)$ than young single women $(10.3 \%)$ had used Psychosocial Resources, whereas the reverse was true in older participants (female: 9.3\%; males: 4.6\%). Moreover, younger married males (3.5\%) reported using Psychosocial Resources less than younger married females $(10.6 \%) \quad(O R=0.937, S E=0.031,95 \%$ CI $(0.882,0.996)$, $p=.035)$. Lastly, more young (33.5\%) $(O R=0.963, S E=$ $0.009,95 \%$ CI $(0.946,0.980), p<.001)$ and single $(37.3 \%)$ $(O R=0.36, S E=0.277,95 \%$ CI $(0.186,0.551), p<.001)$ men and women reported that they would use Psychosocial Resources in the future compared to older $(14.8 \%)$ and married (18.2\%) men and women.

Are age, gender, and marital status proxies for prognostic variables?

Stage and Treatment did not simultaneously correlate significantly with IVs and DVs for any of our analyses. Because this condition was not met, and they could not be considered proxies, we did not adjust our HLM analyses.

\section{Discussion}

We found that marital status buffers or reduces common problems, as it often buffers cancer patients' distress 


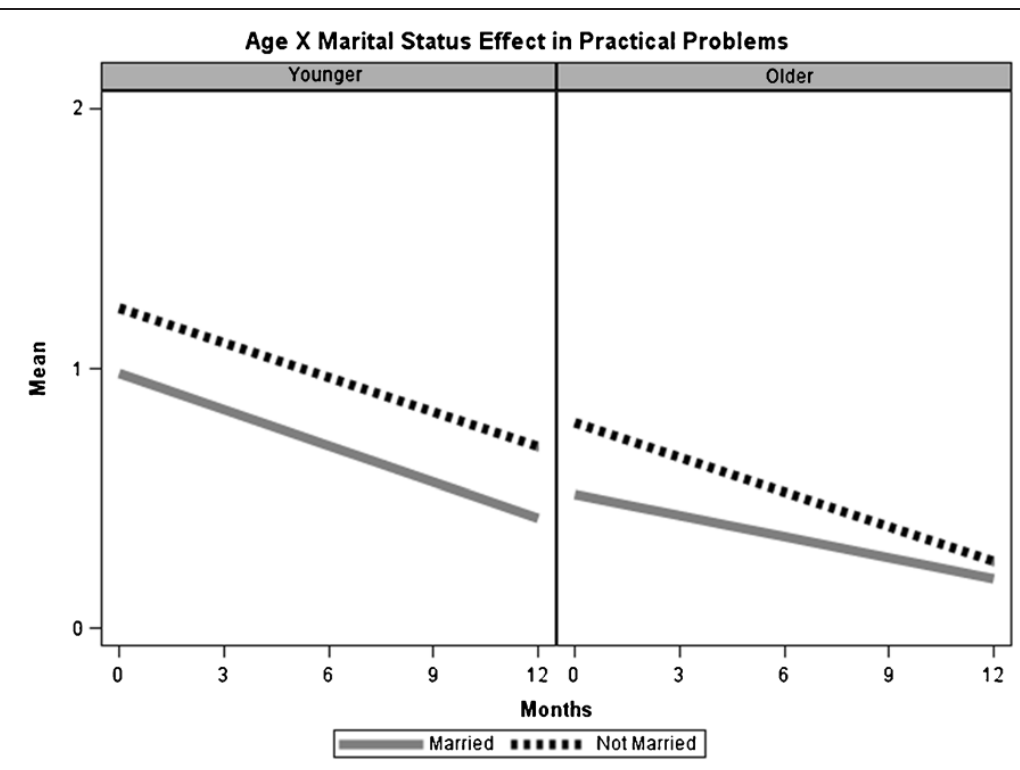

Figure 3 Two-way interaction (Age x Marital status) on changes in Practical problems over time.

$[3,40]$ and unmet needs [27,31-34]; however, age differences impacted this relationship. Similarly, older age buffers common practical problems but differences exist between males and females. Lastly, not only younger women, but also younger men reported higher past and future use of our Psychosocial Resources Program. Stage

Table 4 Results from hierarchical linear model analysis of the impact of age, sex, and marital status on report of psychosocial problems at baseline and over 12 months $(\mathrm{N}=1196)$

\begin{tabular}{|c|c|c|c|c|}
\hline & \multicolumn{3}{|c|}{ HLM on psychosocial problems } & \multirow[t]{2}{*}{ ES } \\
\hline & Estimate & $T$-value & $P$ & \\
\hline \multicolumn{5}{|l|}{ Baseline } \\
\hline Age & -0.02 & -5.52 & $<.0001$ & -0.01 \\
\hline Sex & 0.25 & 2.36 & 0.02 & 0.15 \\
\hline Marital Status & -0.01 & -0.12 & 0.90 & -0.01 \\
\hline Age $\times$ Sex & -0.0004 & -0.06 & 0.95 & -0.0002 \\
\hline Age $\times$ Marital Status & -0.01 & -1.15 & 0.25 & -0.01 \\
\hline Sex $\times$ Marital Status & 0.33 & 1.58 & 0.11 & 0.20 \\
\hline Age $\times$ Sex $\times$ Marital Status & 0.02 & 1.21 & 0.23 & 0.01 \\
\hline \multicolumn{5}{|l|}{ Over 12 Months } \\
\hline Time & -0.05 & -7.27 & $<.0001$ & -0.03 \\
\hline Age $\times$ Time & 0.0002 & 0.49 & 0.62 & 0.0001 \\
\hline Sex $\times$ Time & -0.007 & -0.56 & 0.57 & -0.004 \\
\hline Marital Status $\times$ Time & -0.03 & -2.05 & 0.04 & -0.02 \\
\hline Age $\times$ Sex $\times$ Time & -0.002 & -2.09 & 0.04 & -0.001 \\
\hline Age $\times$ Marital Status $\times$ Time & -0.001 & -0.63 & 0.53 & -0.001 \\
\hline Sex $\times$ Marital Status $\times$ Time & -0.03 & -1.38 & 0.17 & -0.02 \\
\hline $\begin{array}{l}\text { Age } \times \text { Sex } \times \text { Marital } \\
\text { Status } \times \text { Time }\end{array}$ & 0.001 & 0.56 & 0.58 & 0.001 \\
\hline
\end{tabular}

of disease and type of treatment did not explain our results.

Analyzing common problems over time and identifying people at risk for common problems may guide clinicians in targeting interventions toward people who need them most [26]. It allows us to deconstruct elements of need so that we can offer appropriate practical as well as psychological help. For instance, in this study our findings suggest that providing younger single males and females access to practical support (e.g. help with finances), and younger men but women of all ages greater access to psychological support may be beneficial. These associations and interventions based on these findings may also impact distress as we found that the more psychosocial and practical problems patients reported, the higher their distress, anxiety, and depression levels at baseline. Psychosocial and practical problems declined over time and correlated with declines in distress, depression and anxiety.

This study is the first longitudinal investigation of common problems in patients new to the TBCC. The large sample size and longer follow-up period have enabled us to refine previous knowledge in this area. Similar to others, we found that common practical problems include finances and drug coverage [21,27,29,35], with work/ school only a concern for younger people [27]. At baseline older people had considerably fewer problems, as did married people, resulting in the highest prevalence of practical problems in young, single people, particularly women. Marital status findings are consistent with other reports in the literature $[21,27,33,53]$, but we add interactions with age to extend this literature. Younger and single people may have lower incomes, less financial stability if they need to leave work for long periods of time, and greater 


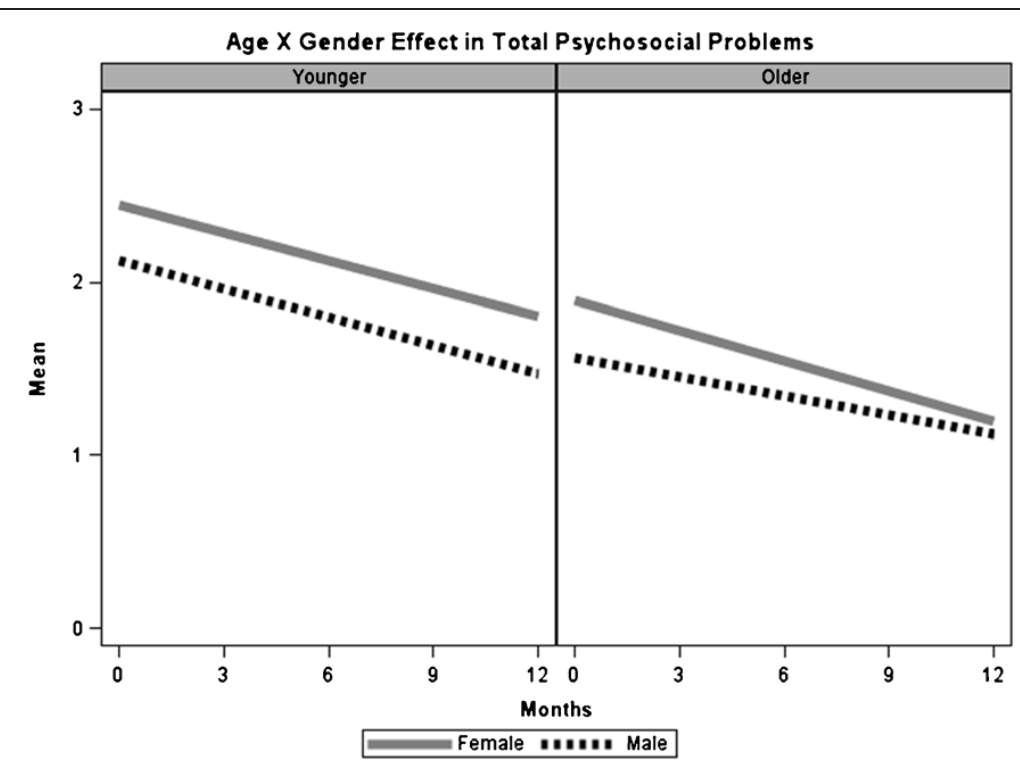

Figure 4 Two-way interaction (Age $x$ Sex) on changes in Psychosocial problems over time.

responsibility for young children. Cancer may disrupt their ability to handle all of these competing demands, so practical help might lead to the most positive improvements.

For psychosocial problems, younger patients reported greater psychosocial problems than older patients, while women reported greater psychosocial problems than men at baseline. Few psychosocial resources target specifically young men and women with support groups or counseling interventions [54,55], and anecdotally young patients often report that they feel they have nothing in common with older people with cancer in support groups. Again, other reports have consistently shown more psychosocial problems in women [24,26,37], perhaps due to an under-reporting bias in males $[34,56]$ or due to a greater tendency in women to focus on processing emotions [57].

The picture becomes more complex when we look at our novel data investigating changes over 12 months. In general, practical and psychosocial problems improved, with the sharpest improvement in the first threemonths, although some problems did not ease on their own. Patients endorsed financial problems often and endorsements remained high over time, even though in Canada patients have public health benefits. Younger, single patients endorsed the most practical problems at baseline and remained the most elevated at 12 months. Younger females endorsed the most psychosocial problems at baseline and remained the most elevated at 12 months. Perhaps these results indicate that neither group currently receives the help they need. Interventions that include help with practical aspects of going through treatment for young single women might improve their distress.
Of the psychosocial problems, worry about friends and family, and difficulty with sleep, remained high as patients underwent a variety of treatments. It is interesting to note that the most common psychosocial problem endorsed was worry about friends and family, a difficulty rarely addressed by health practitioners. Endorsement of this worry also did not decline dramatically over time, with over 30\% still reporting it at 12 months. Older males improved the least in psychosocial problems; however, they did not report high levels of problems at baseline.

Lastly, report of use of the Psychosocial Resources Department at baseline reflected some of these findings. More young single men than young single women reported using Psychosocial Resources, whereas the reverse was true in older participants. This is an unusual finding, perhaps reflecting the prominent erectile dysfunction services offered, and further investigation could document which services young men accessed throughout the year. More young and single men and women reported interest in future use. These results mimic their reports of greater problems. However, older patients may not access services due to experiencing greater barriers in transportation or low caregiver help [58]. Apparently, being married reduces rates of reported current and future interest in the use of services, reflecting some of the buffering seen in the low endorsements of practical problems in married people. Future research could also examine the tumour type of the younger people endorsing use of psychosocial resources which is beyond the scope of this paper. Additionally, future research could examine whether older patients perceived greater barriers to access.

These new findings have implications for cancer-care teams who may want to prioritize resources at the time of 
initial diagnosis toward helping young, single men and women access services to help with resource and financial concerns. For younger single patients, a diagnosis of cancer could result in significant loss in income while expenses such as child care, food, and transportation continue to accrue. These findings challenge us to examine whether resources provided are sufficient for the burden these groups experience. Linking with community programs, providing appropriate childcare or housekeeping services, and enhancing support for basic needs could help significantly reduce the burden and distress of these at-risk groups. Older single patients improved to a similar level as older married patients in this study--they may be more able to handle practical concerns as they suffer less income loss if retired, tend to be more financially stable, and have good medical coverage here in Canada. However, examining carefully barriers to access is important to consider when providing services to older people.

Women of all ages need psychosocial support at the time of diagnosis, but we should not neglect younger men, as they have high practical needs at diagnosis and are using our Psychosocial Resources even more than young women. Innovative psychosocial programs could target this group that is at-risk for sustained problems, since historically men are less likely to access supportive care services on their own. Our care team offers specific therapy programs for men with prostate cancer who have erectile dysfunction which may, in part, account for this unusual finding $[59,60]$. Discussion groups or educational opportunities, that provide a point of entry into the care system, may also be attractive to men. When administrators better understand the needs of a range of patient groups, they can develop more suitable and effective programs. Clinically, these data identify problems and risk groups so intervention can happen earlier--which may result in improved coping and savings to the health care system as fewer crisis interventions may occur.

Although this study has strengths, including a large sample size, relatively high accrual rate, varied cancer diagnoses, and 12-month follow-up, only $72 \%$ of eligible participants consented to the study. There was a significant drop-out or missing data rate, which resulted in only $56.5 \%$ of the original sample (676/1196) being assessed at the final follow-up: some lost due to death or progression of illness, others missed follow-ups, a small group did not continue. However, HLM analysis mitigated this loss in generalizability by using data from all patients who provided at least one assessment in the analysis. The sample is also not representative of breast and lung patients because these tumour groups attended an outpatient clinic in a different location. This study used a measure that assessed the presence of problems in the week prior to questionnaire completion. Jacobsen et al. (2005) suggests that assessing those problems for which individuals want assistance may be more beneficial [18].

Lastly, because this is a mixed cancer sample in a usual-care cancer centre setting, the frequency of cancer types varied. Our goals were to provide evidence for a general cancer population and services offered in a general cancer setting. Certain cancers (testicular, prostate, breast) are gender-specific. It is not possible to adjust for this in an analysis examining gender. However, a larger number of participants in the current study had cancers that are not gender-specific (747 of 1196). Some cancers are age-correlated, and again, it is not possible to adjust for this in an analysis examining age. Other cancers are too rare in this sample for adjustment. As such, age effects may in part reflect the influence of those types of cancers that are age-dependent, and gender effects may in part reflect the influence of those types of cancers that are gender-specific. Further research could investigate larger samples of non-gender- and age-specific cancers.

\section{Conclusions}

As part of a comprehensive Screening for Distress program, we investigated these associations between common practical and psychosocial problems and interactions with marital status, sex, and age during usual care. Although patients completed a screening questionnaire, we did not triage with referral to psychosocial resources, as our goals were to provide a naturalistic picture. This work informs clinical programming decisions, and we have identified several risk groups (young single women, and young men) to target with innovative interventions.

\section{Competing interest}

The authors declare that they have no competing interests.

\section{Authors' contributions}

Study conception and design: LEC, SLG, BDB, JGD. Provision of study materials or patients: LEC, SLG, BD. Collection and assembly of data: SMB, JAS. Data analysis and interpretation: JGD, AW, LZ, EN. Manuscript writing: JGD, AW, KR. All authors read and approved the final manuscript.

\section{Acknowledgements}

We wish to acknowledge grants from Alberta Health Services and the Alberta Cancer Foundation Research Initiatives Program. Dr. Carlson holds the Enbridge Research Chair in Psychosocial Oncology, co-funded by the Alberta Cancer Foundation and the Canadian Cancer Society Alberta/NWT Division. She is also an Alberta Heritage Foundation for Medical Research Health Scholar. Dr. Giese-Davis holds a recruitment and retention grant from The Alberta Cancer Research Institute \#4739 and \#24397. Dr Waller is funded by a Canadian Institutes of Health Research Psychosocial Oncology Research Training (PORT) Fellowship and the Enbridge Research Chair in Psychosocial Oncology, Tom Baker Cancer Centre and the University of Calgary. Ms. Groff is funded by a Canadian Institutes of Health Research Psychosocial Oncology Research Training (PORT) Fellowship. Thanks to Research Assistants Andrea Williams, Paula McQuaid, Paula Jones, Agnes Sroczynska, Johan Halland, Lisa Priebe, Samantha Billingsley, Jennifer McCormick, and statistical advice from Helena C. Kraemer. 


\section{Author details}

'Department of Psychosocial Resources, Tom Baker Cancer Centre, Calgary, Canada. ${ }^{2}$ Department of Oncology, University of Calgary, Calgary, California. ${ }^{3}$ Department of Psychiatry and Behavioral Sciences, Stanford University, Halifax, Nova Scotia, Canada. ${ }^{4}$ Department of Psychology, Dalhousie University, Stanford, California. ${ }^{5}$ Department of Psychosocial Resources, Holy Cross Site, 2202 2nd St. S.W, Calgary, Alberta T2S 3C1, Canada.

Received: 21 February 2012 Accepted: 22 September 2012 Published: 2 October 2012

\section{References}

1. Holland JC, Andersen B, Breitbart WS, Compas B, Dudley MM, Fleishman S, Fulcher CD, Greenberg DB, Greiner CB, Handzo GF, Hoofring L, Jacobsen PB, Knight SJ, Learson K, Levy MH, Loscalzo MJ, Manne S, McAllister-Black R, Riba MB, Roper K, Valentine AD, Wagner LI, Zevon MA: Distress Management. J Natl Compr Canc Netw 2010, 8(4):448-485.

2. Zabora J, Brintzenhofeszoc K, Curbow B, Hooker C, Piantadosi S: The prevalence of psychological distress by cancer site. Psychooncology 2001, 10:19-28,

3. Graves KD, Arnold SM, Love CL, Kirsh KL, Moore PG, Passik SD: Distress screening in a multidisciplinary lung cancer clinic: prevalence and predictors of clinically significant distress. Lung Cancer 2007, 55(2):215-224

4. Carlson LE, Angen M, Cullum J, Goodey E, Koopmans J, Lamont L, MacRae JH, Martin M, Pelletier G, Robinson J, Simpson JS, Speca M, Tillotson L, Bultz BD: High levels of untreated distress and fatigue in cancer patients. Br J Cancer 2004, 90(12):2297-2304.

5. Carlson LE, Groff SL, Maciejewski O, Bultz BD: Screening for distress in lung and breast cancer outpatients: a randomized controlled trial. J Clin Oncol 2010, 28(33):4884-4891

6. Passik S, Dugan W, McDonald M, Rosenfeld B, Theobald D, Edgerton S: Oncologists' recognition of depression in their patients with cancer. J Clin Oncol 1998, 16(4):1594-1600.

7. Sollner W, DeVries A, Steixner E, Lukas P, Sprinzl G, Rumpold G, Maislinger S: How successful are oncologists in identifying patient distress, perceived social support, and need for psychosocial counselling? Br J Cancer 2001, 84(2):179-185

8. Newell S, Sanson-Fisher RW, Girgis A, Bonaventura A: How well do medical oncologists' perceptions reflect their patients' reported physical and psychosocial problems? Data from a survey of five oncologists. Cancer 1998, 83(8):1640-1651.

9. Fallowfield $L$, Ratcliffe $D$, Jenkins $V$, Saul J: Psychiatric morbidity and its recognition by doctors in patients with cancer. $\mathrm{Br} J$ Cancer 2001 84(8):1011-1015

10. Keller M, Sommerfeldt S, Fischer C, Knight L, Riesbeck M, Lowe B, Herfarth C, Lehnert T: Recognition of distress and psychiatric morbidity in cancer patients: a multi-method approach. Ann Oncol 2004, 15(8):1243-1249.

11. Shim EJ, Shin YW, Jeon HJ, Hahm BJ: Distress and its correlates in Korean cancer patients: pilot use of the distress thermometer and the problem list. Psychooncology 2008, 17(6):548-555.

12. Lam WW, Shing YT, Bonanno GA, Mancini AD, Fielding R: Distress trajectories at the first year diagnosis of breast cancer in relation to 6 years survivorship. Psychooncology 2012, 21(1):90-99.

13. Von Essen L, Larsson G, Oberg K, Sjoden PO: 'Satisfaction with care': associations with health-related quality of life and psychosocial function among Swedish patients with endocrine gastrointestinal tumours. Eur J Cancer Care (Engl) 2002, 11(2):91-99.

14. Faller $H$, Bulzebruck $H$, Drings $P$, Lang $H$ : Coping, distress, and survival among patients with lung cancer. Arch Gen Psychiatry 1999, 56(8):756-762.

15. Mitchell AJ, Vahabzadeh A, Magruder K: Screening for distress and depression in cancer settings: 10 lessons from 40 years of primary-care research. Psychooncology 2011, 20:572-584.

16. Kobayashi K, Morita S, Shimonagayoshi M, Kobayashi M, Fujiki Y, Uchida Y, Yamaguchi K: Effects of socioeconomic factors and cancer survivors' worries on their quality of life (QOL) in Japan. Psychooncology 2008, 17(6):606-611

17. Ransom S, Jacobsen PB, BoothJones M: Validation of the distress thermometer with bone marrow transplant patients. Psychooncology 2006, 15(7):604-612

18. Jacobsen PB, Donovan KA, Trask PC, Fleishman SB, Zabora J, Baker F, Holland JC: Screening for psychologic distress in ambulatory cancer patients. Cancer 2005, 103(7):1494-1502.
19. Tuinman MA, Gazendam-Donofrio SM, Hoekstra-Weebers JE: Screening and referral for psychosocial distress in oncologic practice: use of the Distress Thermometer. Cancer 2008, 113(4):870-878

20. Whelan TJ, Mohide EA, Willan AR, Arnold A, Tew M, Sellick S, Gafni A, Levine $M N$ : The supportive care needs of newly diagnosed cancer patients attending a regional cancer center. Cancer 1997, 80(8):1518-1524.

21. Houts PS, Yasko JM, Harvey HA, Kahn SB, Hartz AJ, Hermann JF, Schelzel GW, Bartholomew MJ: Unmet needs of persons with cancer in Pennsylvania during the period of terminal care. Cancer 1988, 62(3):627-634.

22. Minstrell M, Winzenberg T, Rankin N, Hughes C, Walker J: Supportive care of rural women with breast cancer in Tasmania, Australia: changing needs over time. Psychooncology 2008, 17(1):58-65.

23. Griesser AC, Vlastos G, Morel L, Beaume C, Sappino AP, Haller G: Sociodemographic predictors of high support needs in newly diagnosed breast cancer patients. Eur J Cancer Care (Engl) 2010, 20(4):466-474

24. Mclllmurray M, Thomas C, Francis B, Morris S, Soothill K, Al-Hamad A: The psychosocial needs of cancer patients: findings from an observational study. Eur J Cancer Care 2001, 10(4):261-269.

25. Lobb EA, Joske D, Butow P, Kristjanson LJ, Cannell P, Cull G, Augustson B: When the safety net of treatment has been removed: patients' unmet needs at the completion of treatment for haematological malignancies. Patient Educ Couns 2009, 77(1):103-108.

26. McDowell ME, Occhipinti S, Ferguson M, Dunn J, Chambers SK: Predictors of change in unmet supportive care needs in cancer. Psychooncology 2010, 19(5):508-516

27. Houts PS, Yasko JM, Kahn SB, Schelzel GW, Marconi KM: Unmet psychological, social, and economic needs of persons with cancer in Pennsylvania. Cancer 1986, 58(10):2355-2361.

28. Longo CJ, Fitch M, Deber RB, Williams AP: Financial and family burden associated with cancer treatment in Ontario, Canada. Support Care Cancer 2006, 14(11):1077-1085.

29. Jatoi A, Novotny P, Cassivi S, Clark MM, Midthun D, Patten CA, Sloan J, Yang P: Does Marital Status Impact Survival and Quality of Life in Patients with Non-Small Cell Lung Cancer? Observations from the Mayo Clinic Lung Cancer Cohort. Oncologist 2007, 12(12):1456-1463.

30. Thewes B, Butow P, Girgis A, Pendlebury S: The psychosocial needs of breast cancer survivors; a qualitative study of the shared and unique needs of younger versus older survivors. Psycho-Oncology 2004, 13(3):177-189.

31. Barg FK, Cronholm PF, Straton JB, Keddem S, Knott K, Grater J, Houts P, Palmer SC: Unmet psychosocial needs of Pennsylvanians with cancer: 1986-2005. Cancer 2007, 110(3):631-639.

32. Siegel K, Karus DG, Raveis VH, Christ GH, Mesagno FP: Depressive distress among the spouses of terminally ill cancer patients. Cancer Pract 1996, 4:25-30.

33. Mor V, Allen SM, Siegel K, Houts P: Determinants of need and unmet need among cancer patients residing at home. Health Serv Res 1992, 27(3):337-360.

34. Keller M, Henrich G: Illness-related distress: does it mean the same for men and women? Gender aspects in cancer patients' distress and adjustment. Acta Oncol 1999, 38(6):747-755.

35. Longo C, Deber R, Fitch M, Williams A, D'Souza D: An examination of cancer patients monthly out-of-pocket costs in Ontario, Canada. Eur J Canc Care 2007, 16(6):500-507.

36. Aranda S, Schofield $P$, Weih $L$, Yates $P$, Milne D, Faulkner $R$, Voudouris N Mapping the quality of life and unmet needs of urban women with metastatic breast cancer. Eur J Cancer Care (Engl) 2005, 14:211-222.

37. Sanson-Fisher R, Girgis A, Boyes A, Bonevski B, Burton L, Cook P: The unmet supportive care needs of patients with cancer. Supportive Care Review Group. Cancer 2000, 88(1):226-237.

38. Armes J, Crowe M, Colbourne L, Morgan H, Murrells T, Oakley C, Palmer N, Ream E, Young A, Richardson A: Patients' supportive care needs beyond the end of cancer treatment: a prospective, longitudinal survey. J Clin Oncol 2009, 27(36):6172-6179.

39. Gore JL, Krupski T, Kwan L, Maliski S, Litwin MS: Partnership status influences quality of life in low-income, uninsured men with prostate cancer. Cancer 2005, 104(1):191-198.

40. Wittenberg L, Yutsis M, Taylor S, Giese-Davis J, Bliss-Isberg C, Star P, Spiege D: Marital Status Predicts Change in Distress and Well-being in Women Newly Diagnosed With Breast Cancer and Their Peer Counselors. Breast J 2010, 16(5):481-9. 
41. Giese-Davis J, Hermanson K, Koopman C, Weibel D, Spiegel D: Quality of couples' relationship and adjustment to metastatic breast cancer. J Fam Psychol 2000, 14:251-266

42. Harrison JD, Young JM, Price MA, Butow PN, Solomon MJ: What are the unmet supportive care needs of people with cancer? A systematic review. Support Care Cancer 2009, 17(8):1117-1128.

43. Bultz BD, Groff SL: Screening for Distress, the 6th Vital Sign in oncology: from theory to practice. Oncology Exchange 2009, 8(1):1-8.

44. Carlson LE, Waller A, Groff SL, Giese-Davis J, Bultz BD: What goes up doesn't always come down: Patterns of distress, physical and psychosocial morbidity in people with cancer over a one year period. Psycho-oncology 2011, Epub early view (10.1002/pon.2068).

45. Waller A, Williams AD, Groff SL, Bultz BD, Carlson LE: Screening for Distress, the 6th Vital Sign: Examining self-referral to supportive care resources by cancer patients. Psycho-oncology 2011, Epub early view (10.1002/pon.2102).

46. National Comprehensive Cancer Network: Practice guidelines in oncology, version 1.2002: Distress management. National Comprehensive Cancer Network Inc; 2002. http://www.nccn.org/professionals/physician_gls/ f_guidelines.asp\#supportive.

47. Vodermaier A, Linden W, Siu C: Screening for emotional distress in cancer patients: a systematic review of assessment instruments. J Natl Cancer Inst 2009, 101(21):1464-1488.

48. Mitchell AJ: Pooled results from 38 analyses of the accuracy of distress thermometer and other ultra-short methods of detecting cancer-related mood disorders. J Clin Oncol 2007, 25:4670-81.

49. Linden W, Vodermaier AA, McKenzie R, Barroetavena MC, Yi D, Doll R: The Psychosocial Screen for Cancer (PSSCAN): Further validation and normative data. Health Qual Life Outcomes 2009, 7(16):1-8.

50. Linden W, Yi D, Barroetavena MC, MacKenzie R, Doll R: Development and validation of a psychosocial screening instrument for cancer. Health Qual Life Outcomes 2005, 3:54.

51. Gibbons RD, Hedeker D, Elkin I, Waternaux C, Kraemer HC, Greenhouse JB, Shea MT, Imber SD, Sotsky SM, Watkins JT: Some conceptual and statistical issues in analysis of longitudinal psychiatric data. Application to the NIMH treatment of Depression Collaborative Research Program dataset Arch Gen Psychiatry 1993, 50(9):739-750.

52. Kraemer $\mathrm{HC}$, Blasey $\mathrm{CM}$ : Centring in regression analyses: a strategy to prevent errors in statistical inference. Int J Meth Psychiatr Res 2004, 13(3):141-151.

53. Mor $V$, Masterson-Allen $S$, Houts $P$, Siegel $K$ : The changing needs of patients with cancer at home. A longitudinal view. Cancer 1992, 69(3):829-838.

54. Thomas DM, Albritton KH, Ferrari A: Adolescent and young adult oncology: an emerging field. J Clin Oncol 2010, 28(32):4781-4782.

55. Zebrack BJ, Block R, Hayes-Lattin B, Embry L, Aguilar C, Meeske KA, Li Y, Butler M, Cole S: Psychosocial service use and unmet need among recently diagnosed adolescent and young adult cancer patients. Cancer 2012, doi:10.1002/cncr.27713.

56. Goldzweig G, Andritsch E, Hubert A, Brenner B, Walach N, Perry S, Baider L: Psychological distress among male patients and male spouses: what do oncologists need to know? Annals of Oncology 2010, 21(4):877-883.

57. Lieberman MA: Gender and online cancer support groups: issues facing male cancer patients. J Cancer Educ 2008, 23(3):167-171.

58. Ellis J, Lin J, Walsh A, Lo C, Shephard FA, Moore M, Li M, Gagliese L, Zimmermann C, Rodin G: Predictors of Referral for Specialized Psychosocial Oncology Care in Patients With Metastatic Cancer: The Contributions of Age, Distress and Marital Status. Journal of Clinical Oncology 2009, 27(5):699-705.

59. Culos-Reed SN, Robinson JL, Lau H, O'Connor K, Keats MR: Benefits of a physical activity intervention for men with prostate cancer. J Sport Exerc Psychol 2007, 29(1):118-127.

60. Elliott S, Latini DM, Walker LM, Wassersug R, Robinson JW, ADT Survivorship Working Group: Androgen deprivation therapy for prostate cancer: recommendations to improve patient and partner quality of life. J Sex Med 2010, 7(9):2996-3010.

\section{doi:10.1186/1471-2407-12-441}

Cite this article as: Giese-Davis et al:: Screening for distress, the 6th vital sign: common problems in cancer outpatients over one year in usual care: associations with marital status, sex, and age. BMC Cancer 2012 $12: 441$.

\section{Submit your next manuscript to BioMed Central and take full advantage of:}

- Convenient online submission

- Thorough peer review

- No space constraints or color figure charges

- Immediate publication on acceptance

- Inclusion in PubMed, CAS, Scopus and Google Scholar

- Research which is freely available for redistribution 